\title{
Rapid nitrogen fixation by canopy microbiome in tropical forest determined by both phosphorus and molybdenum
}

\author{
Daniel E. Stanton (D) ${ }^{1,2,6}$ Sarah A. Batterman (D) $, 1,3,4,5$ Joseph C. Von Fischer, ${ }^{6}$ and Lars O. Hedin ${ }^{1}$ \\ ${ }^{1}$ Department of Ecology and Evolutionary Biology, Princeton University, Princeton, New Jersey 08544 USA \\ ${ }^{2}$ Department of Ecology, Evolution and Behavior, University of Minnesota-Twin Cities, Saint Paul, Minnesota 55108 USA \\ ${ }^{3}$ School of Geography and Priestley International Centre for Climate, University of Leeds, Leeds LS2 $95 T$ United Kingdom \\ ${ }^{4}$ Smithsonian Tropical Research Institute, Ancon, Panama \\ ${ }^{5}$ Cary Institute of Ecosystem Services, Millbrook, New York 12545 USA \\ ${ }^{6}$ Department of Biology, Colorado State University, Fort Collins, Colorado 80523 USA
}

Citation: Stanton, D. E., S. A. Batterman, J. C. Von Fischer, and L. O. Hedin. 2019. Rapid nitrogen fixation by canopy microbiome in tropical forest determined by both phosphorus and molybdenum. Ecology 100(9):e02795. 10.1002/ecy.2795

\begin{abstract}
Biological nitrogen fixation is critical for the nitrogen cycle of tropical forests, yet we know little about the factors that control the microbial nitrogen fixers that colonize the microbiome of leaves and branches that make up a forest canopy. Forest canopies are especially prone to nutrient limitation because they are (1) disconnected from soil nutrient pools and (2) often subject to leaching. Earlier studies have suggested a role of phosphorus and molybdenum in controlling biological $\mathrm{N}$-fixation rates, but experimental confirmation has hitherto been unavailable. Here we present the results of a manipulation of canopy nutrient availability. Our findings demonstrate a primary role of phosphorus in constraining overall $\mathrm{N}$ fixation by canopy cyanobacteria, but also a secondary role of molybdenum in determining per-cell fixation rates. A conservative evaluation suggests that canopy fixation can contribute to significant $\mathrm{N}$ fluxes at the ecosystem level, especially as bursts following atmospheric inputs of nutrient-rich dust.
\end{abstract}

Key words: biogeochemistry; biological nitrogen fixation; cyanobacteria; molybdenum limitation; phosphorus limitation; phyllosphere; tropical forest canopy.

\section{INTRODUCTION}

Biological nitrogen fixation (BNF) is critical for tropical nitrogen cycling, but we know little about the factors that control the microbial nitrogen fixers that live freely within the microbiome in the vast area of leaf and bark surfaces (tree and epiphyte) that make up a forest canopy environment (phyllosphere). Tropical forest canopies represent one of the largest surface areas that can be colonized by free-living fixers in the land biosphere: they cover $\sim 2$ billion ha globally (Pan et al. 2013) and possess one of the most multilayered (5-15 ha leaf area/ha) and structurally complex biological environments worldwide (Lowman and Rinker 2004).

Life on a leaf in the canopy can be strikingly different from the forest understory. Forest canopy environments are prone to nutrient limitation because they are (1) disconnected from soil nutrient pools (although indirect links through nutrient leaching from leaves may exist; see Benner et al. 2007) and (2) often subject to leaching

Manuscript received 6 December 2018; revised 26 April 2019; accepted 28 May 2019. Corresponding Editor: Steven D. Allison.

${ }^{6}$ E-mail: stan0477@umn.edu by precipitation (Knops et al. 1996, Van Stan et al. 2015; but see Runyan et al. 2013). Canopy soils can develop locally and mitigate these constraints (Nadkarni et al. 2004, Cardelús et al. 2009) and some vascular epiphytes develop structures such as phytotelmata for external water storage (Zotz 2016), but the majority of the canopy surface area has little physical structure for water or nutrient retention. Nutrient inputs are therefore limited to leachates from the plants with access to soil nutrients and atmospheric sources. Thus, canopy biogeochemical cycles are partially decoupled from soil nutrient cycles (Hedin et al. 2009).

Microbial canopy nitrogen fixation, notably by cyanobacteria, has been posited as contributing to the tropical forest nitrogen cycle (Freiberg 1998, Cusack et al. 2009, Hedin et al. 2009, Sullivan et al. 2014); however, reported values are highly variable, ranging from insignificant $\left(<0.1 \mathrm{~kg} \cdot \mathrm{ha}^{-1} \cdot \mathrm{yr}^{-1}\right.$; e.g., Carpenter 1992, Reed et al. 2008) to biogeochemically influential $\left(>5 \mathrm{~kg} \cdot \mathrm{ha}^{-1} \cdot \mathrm{yr}^{-1}\right.$; Forman 1975).

It is less clear why fixation rates appear to range so widely within and between forests and which local environmental factors are needed to trigger fixation rates large enough to be of consequence for the forest nitrogen cycle. One source of variation is the climatic and 
physiognomic range of "tropical forest", from cool montane forests with abundant foliose cyanolichens to hot lowland forests where macrolichens can be nearly absent (Lange et al. 2001) and where free-living bacteria are the primary canopy $\mathrm{N}$ fixers. In the widely distributed lowland forests, likely factors that govern fixation by freeliving bacteria include phyllosphere nutrients (Benner et al. 2007, Reed et al. 2013) as well as light (a source of energy for photosynthesis; Carpenter 1992, Freiberg 1998, Reed et al. 2008) and water (bacteria are poikilohydric; Bentley and Carpenter 1980, Fritz-Sheridan and Portecop 1987, Freiberg 1998, 1999).

Light and water availability vary between canopy microsites, and when the entire forest ecosystem is considered, nutrients offer a more universal constraint. This observation has led to particular interest in two elements, phosphorus and molybdenum, the former central to fueling the fixation reaction and often the constraining nutrient in tropical forests, and the latter a co-factor in the nitrogenase enzyme that catalyzes the fixation reaction (Barron et al. 2009, Wurzburger et al. 2012, Reed et al. 2013). In a Hawaiian montane tropical forest, where fixers are dominated by cyanolichens, fixation increased in response to phosphorus addition (Benner et al. 2007). In a Costa Rican forest, more characteristic of moist lowland communities, Reed et al. (2013) used correlations between BNF rates and leaf tissue nutrient concentrations to propose that colimitation by $\mathrm{P}$ and Mo may occur on leaves.

These studies generally have emphasized the combination of rainfall and leaf/bark leachates as key sources of nutrients such as phosphorus or molybdenum to the canopy microbiome. However, recent findings illustrate that episodic dust inputs, delivered via long-range transport from sources in the African continent, can inject significant quantities of phosphorus (and likely molybdenum) over widespread areas of nutrient-poor tropical forests in the Amazon basin and Central America. This raises the new possibility that dust supply of phosphorus and molybdenum may trigger episodic up-regulation of nitrogen fixation in tropical forest canopies. More broadly, these observations imply that phosphorus and/ or molybdenum availability may govern canopy nitrogen fixation within and across tropical forest canopies, and, by extension, influence the forest nitrogen cycle.

Addressing the role of nutrients in influencing the cyanobacteria-rich epiphytic microbiomes that inhabit the canopies of lowland tropical forests demands an experimental approach that can overcome natural variation caused by bark and/or leaf chemistry, texture and age (Fritz-Sheridan and Portecop 1987, Reed et al. 2013). Because canopy microorganisms are adapted to the rapid turnover of leaves in tropical trees, and thus rapidly colonize new surfaces, it is possible to use nutrient-infused standardized substrates to gain insights into community responses to nutrients.

We here report results from an in situ manipulative experiment, which allows us to evaluate the roles of nutrients in determining the growth and activity of the $\mathrm{N}_{2}$ fixing microbiome of a moist lowland forest canopy. Using a 50-m crane, we installed microbial colonization substrates throughout the canopy (15-40 m height) in two separate 6-month experiments and evaluated the individual and interactive effects of nitrogen, phosphorus, and molybdenum on the rate of atmospheric ${ }^{15} \mathrm{~N}$ fixation by microorganisms. We then use two scaling approaches to estimate ecosystem-wide impacts of our findings more broadly. Our study is the first to experimentally demonstrate that fixation is subject to co-limitation by phosphorus and molybdenum in the forest canopy (as initially proposed by Reed et al. 2013). We further show that this nutrient interaction is mechanistically complex, with phosphorus constraining the overall fixation rate and molybdenum controlling the per-bacterial cell rate of fixation.

\section{Material and Methods}

\section{Site}

Fertilization experiments were conducted at the San Lorenzo Canopy Crane (also known as Fort Sherman Canopy Crane) in San Lorenzo National Park on the Caribbean coast of the Republic of Panama (9.280172 $\mathrm{N}, 79.975393^{\circ} \mathrm{W}, 140 \mathrm{~m}$ elevation). The crane provides access to the canopy of 0.92 ha of evergreen humid forest (mean annual rainfall $\sim 3,200 \mathrm{~mm}$ ) dominated by Brosimum utile (Moraceae) and Manilkara bidentata (Sapotaceae) The site is an Oxisol with high N $\left(1 \mathrm{~g} / \mathrm{m}^{2}\right.$ total) and low phosphorus availability $\left(230 \mathrm{~g} / \mathrm{m}^{2}\right.$ total, $0.15 \mathrm{~g} / \mathrm{m}^{2}$ resin-extractable; Cusack et al. 2018).

\section{Experiment 1: Nitrogen and phosphorus additions}

Epiphyte growth substrates were prepared by adapting the methods of Benner et al. (2007). Nylon stockings were filled with vermiculite to form $40 \mathrm{~cm}$ long cylinders of $4 \mathrm{~cm}$ diameter. Each substrate was then soaked for $12 \mathrm{~h}$ in one of the following treatments: purified water (control), or $\mathrm{PO}_{4}{ }^{-}$as $0.1 \mathrm{~mol} / \mathrm{L} \mathrm{KPO}_{4}(+\mathrm{P}), \mathrm{NH}_{4}{ }^{+}$as 0.8 $\mathrm{mol} / \mathrm{L} \mathrm{CO}\left(\mathrm{NH}_{2}\right)_{2}(+\mathrm{N})$ or $0.1 \mathrm{~mol} / \mathrm{L} \mathrm{KPO}_{4}$ and $0.8 \mathrm{~mol} / \mathrm{L}$ $\mathrm{CO}\left(\mathrm{NH}_{2}\right)_{2}(+\mathrm{P}+\mathrm{N})$ prior to installation. Five canopy height individuals of the most locally abundant trees species, Brosimum utile (Moraceae), were chosen, and within each, four branches of $\sim 30 \mathrm{~cm}$ circumference were chosen within the mid canopy (30-40 m above the ground). The substrates were attached to the upper side of medium sized branches (7-10 cm diameter) in July 2010, and harvested in February 2011. One substrate of each treatment was randomly assigned to each of the four branches per tree, with the constraint that the control treatments were never located directly below nutrient additions.

\section{Experiment 2: Molybdenum and phosphorus additions}

Epiphyte growth substrates were prepared as in Experiment 1, with the following treatments: purified water 
(control), $\mathrm{PO}_{4}{ }^{-}$as $0.1 \mathrm{~mol} / \mathrm{L} \mathrm{KPO}_{4}(+\mathrm{P}), 0.0025 \mathrm{~mol} / \mathrm{L}$ $\mathrm{NaMoO}_{4}(+\mathrm{Mo})$, or $0.1 \mathrm{~mol} / \mathrm{L} \mathrm{KPO}_{4}$ and $0.0025 \mathrm{~mol} / \mathrm{L}$ $\mathrm{NaMoO}_{4}(+\mathrm{P}+\mathrm{Mo})$. To control for counter-ion effects, four additional substrates with $0.1 \mathrm{~mol} / \mathrm{L} \mathrm{NaPO}_{4}$ were used. The same five canopy locations in Experiment 1 were reused, with an additional four subcanopy (15$25 \mathrm{~m}$ ) branches chosen to represent wetter, shaded canopy environments. We reused experiment locations from Experiment 1 in order to minimize site effects. Because the substrates sat above the branch surface allowing for nutrient runoff following substrate removal for Experiment 1, historical effects from reuse of locations were likely minimal. These substrates were installed as above, from February 2011 to September 2011.

\section{Sample processing}

Substrates were harvested after $\sim 6$ months of growth. In the laboratory, the vermiculite was removed and the nylon surfaces rinsed lightly in tap water to remove vermiculite flecks. Individual thalli of liverworts, mosses, and ferns were counted using a dissecting microscope. Cover of cyanobacteria and algae was assessed on a $15 \times 20 \mathrm{~cm}$ grid using a light table. At least three subsamples were taken from each growth substrate and examined under a compound microscope to confirm the presence of cyanobacteria and/or algae, as well as to count the frequency of occurrence of heterocyst cells where nitrogen fixation occurs.

\section{Nitrogen fixation assays}

In addition to the evaluation of cover and heterocyst counts, we measured nitrogen fixation rates on the substrates from Experiment 2. Growth substrates were retrieved from the canopy, slit open and gently rinsed in purified water to remove the vermiculite. For each substrate, a $50-\mathrm{cm}^{2}$ rectangle was cut from the area of densest growth and wetted. This strip was suspended from a hook inside a sealed $100-\mathrm{mL}$ bottle and $25 \mathrm{~mL}$ of $99 \%$ ${ }^{15} \mathrm{~N}_{2}$ gas was injected into each bottle to create a $20 \%$ labelled $\mathrm{N}_{2}$ headspace. To determine background ${ }^{15} \mathrm{~N}$ levels, duplicate strips were also prepared, but injected with air rather than ${ }^{15} \mathrm{~N}_{2}$ gas. All bottles were incubated for $12 \mathrm{~h}$ under constant illumination with photosynthetically available radiation (PAR) lamps. Temperatures within the bottles remained constant $\left(30^{\circ}\right.$ to $\left.33^{\circ} \mathrm{C}\right)$ during the incubation.

After incubation, the strips were removed from the bottles and dried at $50^{\circ} \mathrm{C}$ in a drying oven for $72 \mathrm{~h}$ in individual paper envelopes. Once dried, the biofilms were carefully scraped from the surface using a fine blade and the material ( $\sim 1-3 \mathrm{mg})$ was sealed in pre-weighed aluminum tins. Samples were analyzed in the Smithsonian Tropical Research Institute Soil Laboratory in Panama City, Panama, using a coupled Flash HT Elemental Analyzer and Thermo Scientific Delta V Advantage IRMS (ThermoFisher Scientific, Waltham, MA, USA).
To calculate the proportion of sample $\mathrm{N}$ fixed during the incubations, we assume a two end-member mixing model with no discrimination on fixation:

$$
\begin{aligned}
& \text { Proportion of } \mathrm{N} \text { fixed } \\
& \qquad=\left(\delta^{15} \mathrm{~N}_{\text {sample }}-\delta^{15} \mathrm{~N}_{\text {control }}\right) /\left(\delta^{15} \mathrm{~N}_{\text {air }}-\delta^{15} \mathrm{~N}_{\text {control }}\right)
\end{aligned}
$$

where $\delta^{15} \mathrm{~N}_{\text {air }}$ was calculated for a $20 \%{ }^{15} \mathrm{~N}_{2}$ headspace $(53,570 \%$ o $)$ and $\delta^{15} \mathrm{~N}_{\text {control }}$ is from the mean value of unlabeled samples $(-1.4 \%, n=3)$.

\section{Data analysis}

All data were analyzed using R (R Core Team 2018). Linear models with Mo (or N) and $\mathrm{P}$ as interacting predictors were applied to each of the response variables (cover, heterocyst count, fixation rate). Linear mixed effects models (package nlme) including tree and canopy position as random variables were compared to the linear models using Akaike Information Criterion scores, and in all cases, the simple linear models were preferred. Cover data were arcsine-square root transformed and fixation data were log-transformed to meet assumptions of normality and heteroscedasticity.

\section{RESUlts}

Biological nitrogen fixation rates were greatly enhanced by nutrient additions, increasing by several orders of magnitude with the addition of phosphorus alone (Fig. 1). Fixation rates in the control and $+\mathrm{Mo}$ treatments were low, whereas the $+\mathrm{P}$ and $+\mathrm{P}+\mathrm{Mo}$ increased rates whether expressed on an area or a mass basis, (area normalized, $F_{3,10}=18.77, \quad P<0.0002$, Fig $1 \mathrm{~A}$; mass normalized, $F_{3,10}=8.07, P=0.005$ ).

Moreover, our results show that the overall fixation response emerged from an interactive effect of phosphorus and molybdenum on bacterial nitrogen fixers. The per-area fixation rate was not statistically higher in the $+\mathrm{Mo}+\mathrm{P}$ vs. $+\mathrm{P}$ treatment (Fig. 1), but there was a tendency for higher fixation in the presence of elevated molybdenum. However, in $+\mathrm{P}$ treatments the addition of molybdenum substantially increased the efficiency of fixation, expressed as greater rates on a per-heterocyst (non-photosynthetic cells specialized in biological nitrogen fixation) or a per-mass nitrogen basis (Fig. 2).

We further decomposed the impact of nutrient addition on fixation into effects on either potential fixation activity or microbial abundance (characterized as cover). The relative abundance of heterocysts provides a proxy for maximum (or potential) fixation rates. Heterocysts were present on control as well as nutrient-enriched substrates, but varied significantly in frequency between treatments $\left(F_{3,36}=13.22, P<0.0001\right.$; Fig. $\left.1 b\right)$. Phosphorus addition significantly $(P<0.0003)$ and greatly $(\sim 50 \%)$ increased the relative abundance of heterocysts. 

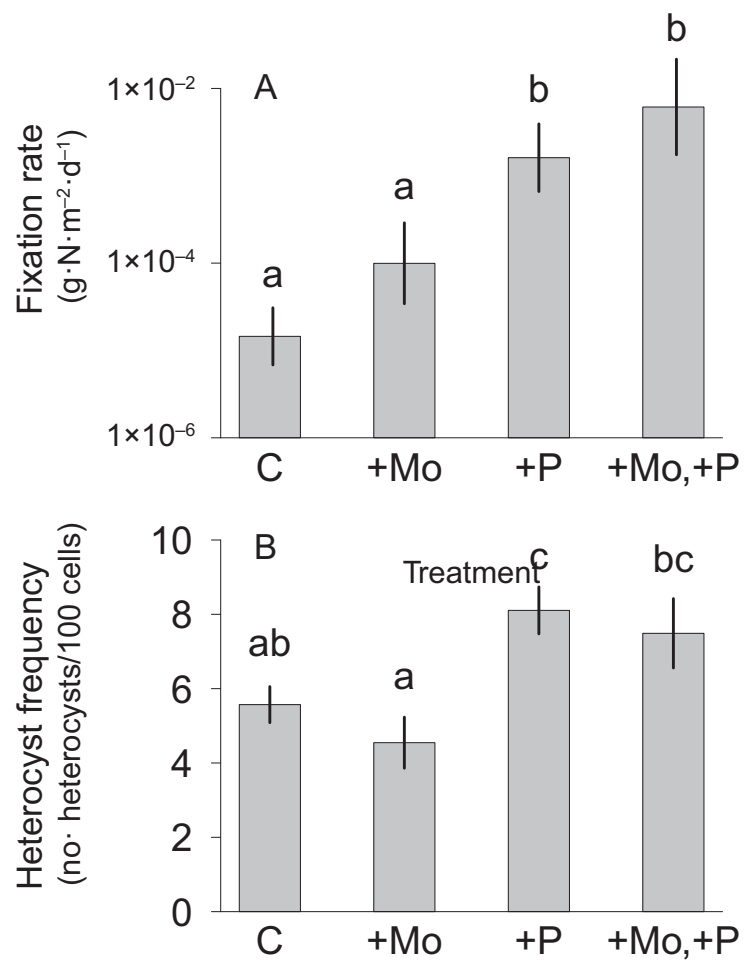

FIG. 1. Responses of (A) log-transformed fixation rates and (B) heterocyst density of subaerial cyanobacterial communities from substrates amended with Mo x $\mathrm{P}$ addition treatments. Phosphorus addition significantly increased both heterocyst density and fixation rates. Lowercase letters indicate significantly different means $(P<0.05)$ from a post-hoc Tukey HSD analysis. $N=5$ for all treatments; error bars show $\pm \mathrm{SE}$.

In contrast, there was a nonsignificant trend toward decreased heterocyst frequency with Mo addition $(P=0.15)$, and no significant interactions between $\mathrm{P}$ and $\mathrm{Mo}(P=0.67)$.

Microbial community cover also varied greatly between treatments. A wide range of organisms were recovered from substrates: bacteria, bryophytes, fern protonemata, and few vascular seedlings (Peperomia sp.). The majority of colonized surfaces were dominated by filamentous cyanobacteria. In control and molybdenum treatments, there was little material recoverable from the substrates with which to even measure fixation rates $\left(<2 \mathrm{mg}\right.$ in $\left.50 \mathrm{~cm}^{2}\right)$. In contrast, $+\mathrm{P}$ treatments were covered in a thick mat of filamentous cyanobacteria (Fig. 3) similar to the nitrogen-fixing communities on tropical forest leaves (Freiberg 1998, 1999, Fürnkranz et al. 2008). Fixer colonization was approximated by assessing the areal extent of cyanobacterial cover, which responded strongly to nutrient treatments (Experiment $1, F_{3,31}=25.26, P<0.0001$; Experiment $2, F_{3,36}=9.45$, $P<0.0001$ ), with up to $90 \%$ of the available surface area colonized within 6 months in $+\mathrm{P}$ treatments (Fig. 4). The addition of phosphorus approximately doubled the extent of cyanobacterial colonization $(P<0.001$,

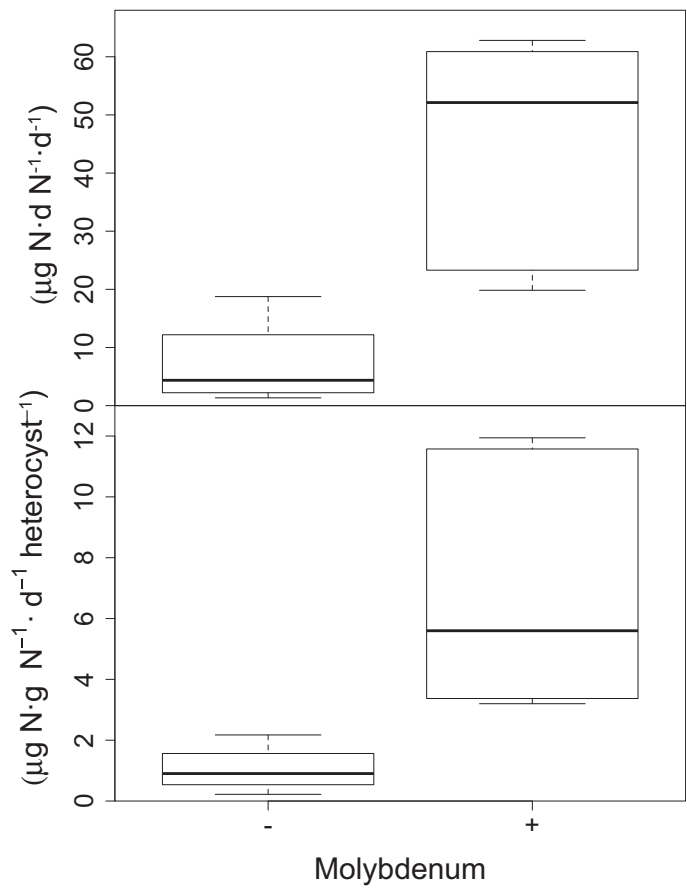

FIG. 2. Addition of molybdenum increases both the overall fixation rates (on mass basis) and efficiency (on a heterocyst basis) of P-fertilized cyanobacterial communities. Box-and-whisker plots show median values (black line), quartile range (box edges), and range of values (whiskers). $N=5$ for all treatments.

Fig. 4A and B), in contrast to the addition of nitrogen, which had a negative impact $(P=0.0243$, Fig. 4A). Contrary to our expectations from nearby leaf litter studies (Barron et al. 2009, Wurzburger et al. 2012), neither molybdenum $(P=0.811)$ nor the interaction of molybdenum and phosphorus $(P=0.807)$ had any effect on cyanobacterial cover (Fig. 4B). There was a weak but significant positive effect of $\mathrm{K}$ as a counter-ion on cover when only $+\mathrm{P}$ treatments were considered $\left(F_{1,20}=5.438\right.$, $P=0.03$ ); however, the effect of $\mathrm{K}$ was much smaller than that of P. Similarly, the presence of $\mathrm{K}$ instead of $\mathrm{Na}$ as a counter-ion significantly increased the heterocyst frequency of the $+\mathrm{P}$ treatment $(F=13.93, P=0.0013)$, but the magnitude of the effect was weak, and the choice of counter-ion did not bias the strong effects of phosphorus and molybdenum.

\section{DisCUSSION}

Our results show strong evidence for regulation of microbial nitrogen fixers within tropical forest canopies by phosphorus availability, but also by an additional interaction with molybdenum. Cyanobacteria were the predominant organism colonizing our experimental substrates, suggesting a high potential for colonization of available surfaces by free-living nitrogen-fixing organisms in these tropical canopies. This dominance by nitrogen 
fixers, accompanied by the consistent production of heterocysts and a trend toward down-regulation of heterocyst cover in response to nitrogen addition, all point to nitrogen limitation being ecologically important throughout

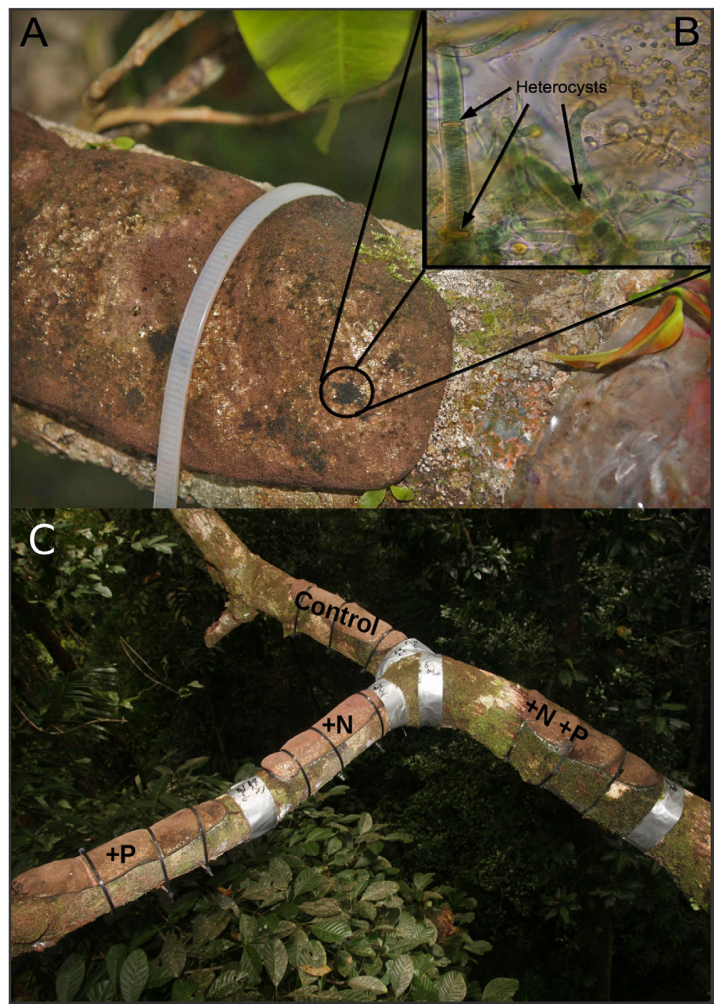

FIG. 3. Artificial substrates placed (A) directly in the canopy were rapidly colonized by cyanobacterial communities composed primarily of (B) filamentous cyanobacteria, which fix nitrogen. (C) Each set of treatments was arranged to ensure homogeneity of environmental conditions and avoid any runoff from positive treatments onto controls. the epiphytic canopy environment. This observation contrasts with the common characterization of tropical forests as generally "nitrogen rich"; the canopy environment appears to be decoupled from soil nutrient conditions, favoring continued nitrogen-fixing activity despite the high nitrogen status of soils and the ecosystem as a whole (Hedin et al. 2009, Brookshire et al. 2012).

Although both phosphorus and molybdenum constrained fixation, they elicited quite different responses and appeared to influence fixation through quite different mechanisms. The impact of $\mathrm{P}$ addition was primarily through increased growth, both of total microbial cover (Fig. 4) and frequency of costly heterocysts (Fig. 1b). In contrast, the addition of molybdenum alone had little effect on total cyanobacteria cover (Fig 4) and in fact showed a trend toward decreasing investment in cyanobacteria heterocysts (Fig. 1b). Interestingly, we found a highly significant impact of molybdenum that was limited to enhancing the efficiency of nitrogen-fixation in phosphorus-rich conditions, expressed on a perheterocyst or per-mass nitrogen basis (Fig. 2).

We propose that these differences reflect the very different biochemical roles and mechanisms of phosphorus and molybdenum as limiting nutrients on fixers and fixation rates. Molybdenum has little biological importance outside of its role as a co-factor in the nitrogenase enzyme, whereas phosphorus is essential to metabolic activity and cellular structure. The phosphorus response suggests that phosphorus effects do not solely arise through alleviation of nitrogen limitation but also a more general constraint on fixer biomass growth that is not resolved by increased nitrogen availability alone. In contrast, the molybdenum response suggests that this nutrient influences nitrogen fixation efficiency, but this increased efficiency does not necessarily translate into growth in the absence of phosphorus.

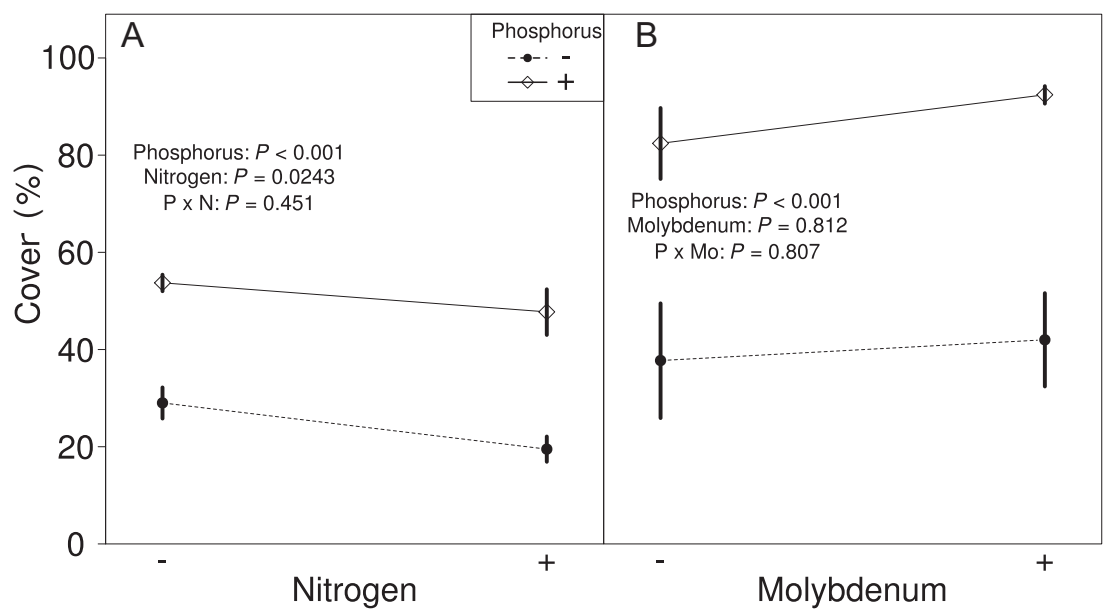

FIG. 4. Interaction plots of cyanobacterial cover in response to (A) $\mathrm{N} x \mathrm{P}$ and (B) Mo x $\mathrm{P}$ nutrient addition experiments. Phosphorus $(+\mathrm{P})$, but not nitrogen $(+\mathrm{N})$ or molybdenum $(+\mathrm{Mo})$ significantly increased total cyanobacterial cover. No significant interactive effects between phosphorus and nitrogen $(+\mathrm{N}+\mathrm{P})$ or between phosphorus and molybdenum $(+\mathrm{Mo}+\mathrm{P})$ were observed. $(\mathrm{A})$ $N=5$ for treatments in Experiment 1 and (B) $N=9$ for Experiment 2 . 
The microbial communities in all treatments were dominated by filamentous cyanobacteria, consistent with reports from phyllospheres (Freiberg 1999) and the use of artificial substrate in other tropical forests (Sanders and Lucking 2002, Lücking and Bernecker-Lücking 2005). Part of the nutrient effect on cyanobacteria colonization and nitrogen fixation may have been caused by differences in initial community composition, but it is difficult for us to separate this effect from that of simple up-regulation of growth and fixation rates. As for new leaves, our substrates were colonized de novo by rapid dispersal of the microbial community. Yet, our experiment was limited to 6 months of community development, which may or may not differ from leaves and bark with more advanced community development. These are important directions for future investigation, but they are unlikely to alter our identification of phosphorus and molybdenum as factors that interactively govern nitrogen fixation.

Our results raise the fundamental question of where the canopy microbiome obtains phosphorus and molybdenum. Leaching from host plant tissues may provide some degree of coupling between soil nutrients and canopy BNF; tropical montane cyanolichen fixation rates responded to experimental manipulations of tree phosphorus content (Benner et al. 2007), indicating a feedback between soil and epiphyte nutrient status in that system. It is well-recognized that leaching from the tissues of host plants can deliver phosphorus, but less is known about whether molybdenum can also be lost from plant tissue in the canopy at ecologically significant rates. By assuming that the leachate P:Mo mirrors the P: Mo stoichiometry of leaf tissue, we can estimate that epiphyte communities experience nutrient inputs in which molybdenum is strongly constrained relative to phosphorus, even when compared to litter and soil in the same forests (Reed et al. 2013).

We next explored whether a second mechanism, the delivery of phosphorus and molybdenum-rich atmospheric particles to the canopy during African-derived "dust events" (Okin et al. 2004, Yu et al. 2015), could trigger increased fixation, as has been suggested for algae in the tropical Atlantic ocean (Bristow et al. 2010). These events, in which large quantities of rock-derived dust is transported by air from phosphorus-rich areas of the Sahara to Central and/or South America, can cause many-fold increases in atmospheric inputs of phosphorus and molybdenum following stoichiometric ratios similar to those used in our experiment (Yu et al. 2015, Westrich et al. 2016). Such dust events likely can cause sudden bursts in canopy fixation, similar to those observed in our phosphorus and molybdenum additions.

The up-regulation of nitrogen fixation that we observed in response to phosphorus and molybdenum offers a mechanism by which episodes of African dust deposition could impact the forest nitrogen cycle across large areas of neotropical forests. We explored this possibility using two calculations: First, we used Yu et al.'s
(2015) 7-yr average measure of dust input from phosphorus-rich regions of Africa (7-39 g P.ha $\left.{ }^{-1} \cdot \mathrm{yr}^{-1}\right)$ and assumed that most dust intercepted by the canopy would be available for assimilation by cyanobacteria. Based on the biomass-to-phosphorus ratio we estimate that dust deposition could support 700-3,900 g/ha, which, based on our fertilization experiment, could increase canopy nitrogen fixation by roughly $2.4-15 \mathrm{~g} \mathrm{~N} \cdot \mathrm{ha}^{-1} \cdot \mathrm{d}^{-1}(1-$ $5 \mathrm{~kg} \mathrm{~N} \cdot \mathrm{ha}^{-1} \cdot \mathrm{yr}^{-1}$ ). Second, we considered the extensive surface area covered by microbes in dense and tall tropical forests. We estimated (Appendix S1) that any event with a quantity of dust input sufficient to stimulate fixation to fully fertilized rates for even a few weeks $(5-10 \%$ of the year) is sufficient to produce nitrogen inputs of $\sim 1-5 \mathrm{~kg} \cdot \mathrm{ha}^{-1} \cdot \mathrm{yr}^{-1}$ assuming moderate microbial cover $(\sim 30 \%$ of available area).

While our calculations are preliminary, both arrive at similar values. Moreover, these values are significant compared to other measures of nitrogen inputs by litter layer fixation (Barron et al. 2009), atmospheric deposition (Cleveland et al. 1999) and potentially even symbiotic fixation over decadal time scales (Batterman et al. 2013, Sullivan et al. 2014). Our findings point to a potential teleconnection between the tropical nitrogen cycle and phosphorus/molybdenum inputs caused by the episodic deposition of dust of western African origin (Yu et al. 2015). Future studies should seek to further resolve the importance of canopy fixation in the nitrogen budget of tropical forests, and its responsiveness to dust events.

Our findings offer new evidence of the canopy microbiome as an important and highly dynamic component of tropical forest ecosystems. The canopy environment houses a microbial community that is able to rapidly establish and fix nitrogen in response to phosphorus fertilization, with enhanced rates in the added presence of molybdenum. The extensive surface of colonizable area in tropical forest canopies means that even transiently high nitrogen fixation rates by canopy micro-organisms may represent an overlooked but crucial component of tropical forest biogeochemistry. This biogeochemical role of the canopy microbiome is not only partially decoupled from soil conditions (unlike symbiotic nitrogen fixation associated with plants), but also mediates the coupling of local (i.e., forest nutrient cycle) and regional (i.e., dust transport) phosphorus and molybdenum cycles.

\section{ACKNOWLEDGMENTS}

D. Stanton and L. Hedin designed the study, D. Stanton set up experiment and all authors collected data. D. Stanton wrote the first draft of the manuscript, and all authors contributed to revisions. D. Stanton was supported by a Princeton University President's Award. S. A. Batterman acknowledges funding from a Carbon Mitigation Initiative young investigator grant (with funding from BP), a University of Leeds University Academic Fellowship, the Natural Environment Research Council (NE/ M019497/1; NE/N012542/1) and the British Council (award 275556724). We would like to thank J. Wright, N. Salazar, O. 
Acevedo, H. Castaneda, M. Samarniego, G. Mendieta, K. Wagner, and E. Sanchez for assistance with canopy access and experimental set-up, B. Turner and D. Agudo for assistance with isotope sample analyses, N. Wurzburger and members of the Hedin lab for helpful discussions and feedback on drafts and two anonymous reviewers for their helpful comments.

\section{Literature Cited}

Barron, A. R., N. Wurzburger, J. P. Bellenger, S. J. Wright, A. M. L. Kraepiel, and L. O. Hedin. 2009. Molybdenum limitation of asymbiotic nitrogen fixation in tropical forest soils. Nature Geoscience 2:42-45.

Batterman, S. A., L. O. Hedin, M. van Breugel, J. Ransijn, and J. S. Hall. 2013. Key role of symbiotic dinitrogen fixation in tropical forest secondary succession. Nature 502:224-227.

Benner, J. W., S. Conroy, C. K. Lunch, N. Toyoda, and P. M. Vitousek. 2007. Phosphorus Fertilization Increases the Abundance and Nitrogenase Activity of the Cyanolichen Pseudocyphellaria crocata in Hawaiian Montane Forests. Biotropica 39:400-405.

Bentley, B. L., and E. J. Carpenter. 1980. Effects of desiccation and rehydration on nitrogen fixation by epiphylls in a tropical rainforest. Microbial Ecology 6:109-113.

Bristow, C. S., K. A. Hudson-Edwards, and A. Chappell. 2010. Fertilizing the Amazon and equatorial Atlantic with West African dust. Geophysical Research Letters 37:L14807.

Brookshire, E. N. J., S. Gerber, D. N. L. Menge, and L. O. Hedin. 2012. Large losses of inorganic nitrogen from tropical rainforests suggest a lack of nitrogen limitation: Nitrogen saturation in tropical rainforests. Ecology Letters 15:9-16.

Cardelús, C. L., M. C. Mack, C. Woods, J. DeMarco, and K. K. Treseder. 2009. The influence of tree species on canopy soil nutrient status in a tropical lowland wet forest in Costa Rica. Plant and Soil 318:47-61.

Carpenter, E. J. 1992. Nitrogen fixation in the epiphyllae and root nodules of trees in the lowland tropical rainforest of Costa Rica. Acta Oecologica 13:153-160.

Cleveland, C. C., et al. 1999. Global Patterns of terrestrial biological nitrogen (N2) fixation in natural ecosystems. Global Biogeochemical Cycles 13:623-634.

Cusack, D. F., W. Silver, and W. H. McDowell. 2009. Biological nitrogen fixation in two tropical forests: ecosystem-level patterns and effects of nitrogen fertilization. Ecosystems 12:1299-1315.

Cusack, D. F., L. Markesteijn, R. Condit, O. T. Lewis, and B. L. Turner. 2018. Soil carbon stocks across tropical forests of Panama regulated by base cation effects on fine roots. Biogeochemistry 137:253-266.

Forman, R. T. T. 1975. Canopy lichens with blue-green algae a nitrogen source in a Colombian rain forest. Ecology 56:11761184.

Freiberg, E. 1998. Microclimatic parameters influencing nitrogen fixation in the phyllosphere in a Costa Rican premontane rain forest. Oecologia 117:9-18

Freiberg, E. 1999. Influence of microclimate on the occurrence of cyanobacteria in the phyllosphere in a premontane rain forest of Costa Rica. Plant Biology 1:244-252.

Fritz-Sheridan, R. P., and J. Portecop. 1987. Nitrogen fixation on the tropical volcano, La Soufriere (Guadeloupe): I. A survey of nitrogen fixation by blue-green algal Microepiphytes and Lichen Endophytes. Biotropica 19:194.

Fürnkranz, M., W. Wanek, A. Richter, G. Abell, F. Rasche, and A. Sessitsch. 2008. Nitrogen fixation by phyllosphere bacteria associated with higher plants and their colonizing epiphytes of a tropical lowland rainforest of Costa Rica. ISME Journal $2: 561-570$

Hedin, L. O., E. N. J. Brookshire, D. N. L. Menge, and A. R. Barron. 2009. The nitrogen paradox in tropical forest ecosystems. Annual Reviews in Ecology, Evolution and Systematics 40:613-635.

Knops, J. M. H., T. H. Nash, and W. H. Schlesinger. 1996. The influence of epiphytic lichens on the nutrient cycling of an oak woodland. Ecological Monographs 66: 159-179.

Lange, O. L., T. G. A. Green, and U. Heber. 2001. Hydrationdependent photosynthetic production of lichens: what do laboratory studies tell us about field performance? Journal of Experimental Botany 52:2033-2042.

Lowman, M., and H. B. Rinker. 2004. Forest canopies. Second edition. Elsevier Academic Press, Burlington, Massachusetts, USA.

Lücking, R., and A. Bernecker-Lücking. 2005. Drip-tips do not impair the development of epiphyllous rain-forest lichen communities. Journal of Tropical Ecology 21:171-177.

Nadkarni, N. M., D. Schaefer, T. J. Matelson, and R. Solano. 2004. Biomass and nutrient pools of canopy and terrestrial components in a primary and a secondary montane cloud forest, Costa Rica. Forest Ecology and Management 198:223-236.

Okin, G. S., N. Mahowald, O. A. Chadwick, and P. Artaxo. 2004. Impact of desert dust on the biogeochemistry of phosphorus in terrestrial ecosystems. Global Biogeochemical Cycles 18:GB2005.

Pan, Y., R. A. Birdsey, O. L. Phillips, and R. B. Jackson. 2013. The structure, distribution, and biomass of the World's forests. Annual Reviews in Ecology, Evolution and Systematics 44:593-622.

R Core Team. 2018. R: A language and environment for statistical computing. R Foundation for Statistical Computing, Vienna, Austria. http://www.R-project.org/

Reed, S. C., C. C. Cleveland, and A. R. Townsend. 2008. Tree species control rates of free-living nitrogen fixation in a tropical rain forest. Ecology 89:2924-2934.

Reed, S. C., C. C. Cleveland, and A. R. Townsend. 2013. Relationships among phosphorus, molybdenum and free-living nitrogen fixation in tropical rain forests: results from observational and experimental analyses. Biogeochemistry 114:135147.

Runyan, C. W., D. Lawrence, K. L. Vandecar, and P. D'Odorico. 2013. Experimental evidence for limited leaching of phosphorus from canopy leaves in a tropical dry forest. Ecohydrology 6:806-817.

Sanders, W. B., and R. Lucking. 2002. Reproductive strategies, relichenization and thallus development observed in situ in leaf-dwelling lichen communities. New Phytologist 155:425435.

Sullivan, B. W., et al. 2014. Spatially robust estimates of biological nitrogen $(\mathrm{N})$ fixation imply substantial human alteration of the tropical N cycle. Proceedings of the National Academy of Sciences USA 111:8101-8106.

Van Stan, J. T., A. Stubbins, T. Bittar, J. S. Reichard, K. A. Wright, and R. B. Jenkins. 2015. Tillandsia usneoides (L.) L. (Spanish moss) water storage and leachate characteristics from two maritime oak forest. Ecohydrology 8:9881004.

Westrich, J. R., et al. 2016. Saharan dust nutrients promote Vibrio bloom formation in marine surface waters. Proceedings of the National Academy of Sciences USA 113:5964 5969.

Wurzburger, N., J. P. Bellenger, A. M. L. Kraepiel, and L. O. Hedin. 2012. Molybdenum and phosphorus interact to 
constrain asymbiotic nitrogen fixation in tropical forests PLoS ONE 7:e33710.

$\mathrm{Yu}, \mathrm{H}$, et al. 2015. The fertilizing role of African dust in the Amazon rainforest: A first multiyear assessment based on data from cloud-aerosol Lidar and infrared pathfinder satellite observations: dust deposition in the Amazon rainforest. Geophysical Research Letters 42:1984 1991.

Zotz, G. 2016. Plants on plants. The biology of vascular epiphytes. Springer Verlag, Berlin, Germany.

\section{SUPPORTING INFORMATION}

Additional supporting information may be found in the online version of this article at http://onlinelibrary.wiley.com/doi/ 10.1002/ecy.2795/suppinfo

\section{Data Availability}

Data are available from the Dryad Digital Repository: https://doi.org/10.5061/dryad.bt5rc79 